\title{
Comparison of water quality in live shellfish retail holding tanks
}

Kelson Mah ${ }^{1}$, Vanessa Karakilic ${ }^{2}$, Fred Shaw ${ }^{2}$ Lorraine McIntyre $^{3}$, Brian Barker ${ }^{4}$, Wayne Sparanese ${ }^{4}$, Dave Hunchak ${ }^{4}$, Stella Lukman ${ }^{4}$, Arthur Demsky ${ }^{5}$, Perry Powers ${ }^{5}$,

1 Lead Author, B. Tech Student, School of Health Sciences, British Columbia Institute of Technology, 3700 Willingdon Ave, Burnaby, BC V5G $3 \mathrm{H} 2$

2 Supervisor, School of Health Sciences, British Columbia Institute of Technology, 3700 Willingdon Ave, Burnaby, BC V5G 3H2

3 Contributor, BC Centre for Disease Control, 655 West $12^{\text {th }}$ Avenue, Vancouver, BC V5Z 4R4

4 Contributor, Ministry of Agriculture, 808 Douglas St, Victoria, BC V8W9B4

5 Contributor, Department of Fisheries and Oceans, 5550268 St, Langley, BC V4W 3X4

\section{Abstract \\ Background}

Water quality in live retail shellfish holding tanks are vital in increasing shellfish quality and reducing risk of shellfish-associated outbreaks. Poor holding tank water conditions may not only cause mortality of shellfish, but also allow for harmful pathogens to contaminate the shellfish, proliferate in the holding tanks, and ultimately potentially affect consumer health. Shellfish are processed and handled at a variety of levels at the retail stage. Therefore, the purpose of this research project is to compare water quality in live retail shellfish holding systems between processing plants and retail food markets. Differences may indicate a need for attention at a particular level in order to effectively and efficiently reduce mortality and disease among shellfish, and thus potentially humans as well.

Methods

30 water samples were taken from the two types of locations with the help of the Department of Fisheries and Oceans (DFO), Ministry of Agriculture, and the BCCDC. These samples were tested for parameters including temperature, $\mathrm{pH}$, nitrites, turbidity, and dissolved oxygen using a LaMotte Fresh Water Aquaculture Kit and a HACH $2100 \mathrm{P}$ turbidimeter. A two-tailed t-test was used to compare the means of each of the parameters among the two types of locations with live shellfish holding tanks. Results

The mean values for all parameters in both retail and processing met the requirements set by the BCCDC. However, temperature and dissolved oxygen showed statistically significant differences between retail markets and processing facilities. Nitrites, $\mathrm{pH}$, and turbidity showed no statistically significant differences between the two types of locations.

Conclusion

Differences in dissolved oxygen may have been due to salt levels, failing recirculation systems, or high levels of organic matter from sanitation issues. Differences in temperature may have been due to differences in holding tank size, or inconsistencies from using two different thermal measuring devices. High levels of nitrites were a concern as well due to overcrowding of holding tanks. More attention may be needed for these issues, especially during certain seasons such as Chinese New Years, in order to lower the risk to public health.

Keywords: shellfish, holding tanks, water quality, processing facility, retail food market, food safety, public health

\section{Introduction}

The growing prevalence of illnesses originating from shellfish is becoming a more prominent concern around the world. Shellfish such as bivalve molluscs concentrate material from the environment around them through their feeding process, and thus act as potential vectors for water-borne agents. The most common illnesses associated with ingesting shellfish are caused by Vibrio parahaemolyticus and nontyphoidal Salmonella (Gosling, 2015, p. 478). Other illnesses associated with ingesting raw shellfish include Hepatitis A, Norovirus, Paralytic Shellfish Poisoning, Diarrhetic Shellfish Poisoning, and Amnesic Shellfish Poisoning (BCCDC, 2012). 
The world has observed an increase in outbreaks originating from shellfish in recent years. Specifically, illnesses such as Vibrio parahaemolyticus infections or Paralytic Shellfish Poisoning are continuing to rise worldwide (Faber, 2012). For example, the Vibrio parahaemolyticus outbreak in British Columbia during the summer of 2015 led to an increase in number of shellfish-related illnesses, resulting in an Oyster ban in Vancouver and a recall of harvested oysters (BCCDC, 2015). Within Canada, British Columbia has also seen a significant and steady increase since 2007 , in which infection rates increased from 0.4 to 1.5 cases per 100000 population (BCCDC, 2014). Significant economic impacts also arise from shellfish-associated outbreaks. One Paralytic Shellfish Poisoning outbreak alone is estimated to cost businesses and fisheries around $\$ 6$ million (Faber, 2012). Unfortunately, it is expected that shellfish-associated outbreaks will continue to grow substantially and affect human health and the economy at a greater degree due to anthropogenic events such as relocation of non-indigenous marine species, eutrophication, and world-wide climate change (Faber, 2012).

The proposed study was brought forward by Lorraine McIntyre from the BCCDC, who had observed dead clams being sold at the retail level. Although dead shellfish are traditionally seen as more of a quality issue rather than a health issue (Oregon Health, n.d.), the health of shellfish should be a concern for consumers. Dead shellfish can be an indicator of poor water quality, or in other words, conditions that may favor contamination of the shellfish and proliferation of potential pathogens that are harmful to human health (BCCDC, 2013). Furthermore, poor water quality may negatively affect the workers who are handling the fish (BCCDC guideline, 2013). Live retail fish holding systems are found in multiple premises along the fish processing chain. Processing plants and retail food markets are examples of establishments that may use live retail fish holding systems. These different types of establishments provide different environments and challenges for holding tank water quality. Therefore, the purpose of this research project is to compare water quality in live retail fish holding systems between processing plants and retail food markets. Differences may indicate a need for attention at the particular level in order to more effectively and efficiently reduce mortality and disease among shellfish, and thus potentially humans as well. Water quality will be determined and measured through several parameters set out by the BCCDC guideline for Live Retail Fish Holding Systems (2013) and the Fish Inspection Regulations (2012). These parameters are: water temperature, $\mathrm{pH}$, dissolved oxygen, nitrites, and turbidity.

In order to control shellfish outbreaks and illnesses, each stage of processing from farm-to-fork must be looked at, and the proper measures implemented to decrease contamination and thus outbreaks. One stage of interest is at the retail level, which includes processing facilities and retail markets.

Therefore, this project will examine the factors and indicators that may lead to shellfish contamination specifically at the retail stage by considering existing research and legislation, as well as implications for the consumer and policy development.

\section{Evidence Review}

Existing legislation

Relevant legislation for retail stores selling bivalve molluscs are few. The Food Safety Act (2015), Public Health Act (2015), and Food Premises Regulation (2013) provide general requirements for food premises. The Fish Inspection Act (2015), Fish Inspection Regulations (2012), and the Canadian Shellfish Sanitation Program (2015) more specifically outline the requirements for seafood, including molluscs. However, the majority of legislation for bivalve molluses is directed at the harvesting stage. Nevertheless, Guidelines and manuals tailored towards bivalve molluscs in retail stores do exist. These include the Canadian Shellfish Sanitation Program- Manual of Operations (2015), BCCDC Reference Manual of Provincial Fish Inspection for Retail Operations in Stores and Restaurants (2012), and BCCDC Guideline for Live Retail Fish Holding Systems (2013). Unfortunately, guidelines are not enforceable. This lack of legislation specifically regarding bivalve mollusc safety in retail outlets is concerning because of post-harvest contamination. In fact, Degolier et al. (2009) 
found that $43 \%$ of surveyed establishments committed violations, including crosscontamination and commingling, both of which have a direct impact on bivalve mollusc safety post-harvest. Therefore, it may be of interest for the government to consider adding to or changing the existing legislation, or to increase efforts in monitoring retail outlets selling shellfish.

\section{Equipment}

The Canadian Shellfish Sanitation Program (CSSP) (2015) provides requirements for wet storage of shellfish applicable at the retail level. This includes the presence of water treatment systems, holding tank specification, handling of shellfish, and labelling. BC Centre for Disease Control's Guideline for Live Retail Fish Holding Systems (2013) has incorporated the requirements outlines in the CSSP and has even created a checklist for inspectors to use during inspection of the retail store to ensure adequate maintenance and condition of live retail fish holding tanks.

\section{Indicators}

Contamination or death of shellfish is largely dependent on the water quality that surrounds them. Just as stringent regulations control shellfish hatcheries, control of water quality in retail wet storage is vital as well to reduce risk of contamination and foodborne illness. Turbidity (Health Canada, 2012), coliforms (Oregon State University, n.d.), and nitrates (BCCDC, 2013) are all indicators of post-processing contamination or inadequate water treatment. Temperature is also an important indicator and control factor because Vibrio parahaemolyticus has been shown to multiply at temperatures above $13-15^{\circ} \mathrm{C}$ (Nelapati, Nelapati, \& Chinnam, 2012, p. 51). Control of hazards in shellfish

Depuration is a purification process that hatcheries implement to deconcentrate any potential contaminants that shellfish such as bivalve molluscs may have filtered by placing them in clean tanks of seawater to allow for natural filtering, resulting in the removal of contaminants (Lee, Lovatelli, \& Ababouch, 2008). Although effective for many contaminants, depuration's efficacy is not pervasive for all pathogens. For instance, depuration was shown to be less effective in removing viruses or naturally occurring Vibrio parahaemolyticus (Lee, Lovatelli, \& Ababouch, 2008). In fact, Huss, Reilly, \& Embarek (2000) found that Vibrio spp. and viruses can accumulate in molluscs even when all preventive measures have been applied. In this way, there is very little a retail store can do to prevent contamination of bivalve molluscs; the onus is on hatcheries and governmental agencies to ensure vibrio levels do not become a risk for human consumers, especially in the summer when waters become warmer (Nelapati, Nelapati, \& Chinnam, 2012, p. 51).

Interestingly, consumers were found to prefer buying depurated products despite studies showing that it is ineffective against viruses and Vibrio parahaemolyticus (Oliveira, Cunha, Castilho, Romalde, \& Pereira, 2011).

Microbiological quality in open air markets vs. hypermarkets

Noroviruses are viruses that are transmitted from person to person or through contaminated food and water. Presence of Norovirus in shellfish indicate human fecal contamination (Public Health Agency of Canada, 2014). At the retail level, it is possible that shellfish become contaminated via infected employees or food handlers. According to Terio et al. (2010), $12.1 \%$ of shellfish samples collected in Italy contained Norovirus. Interestingly, they found that hypermarkets, or supermarkets, had a lower rate of $8.1 \%$ compared to open-air markets and fish shops, at $17.6 \%$ and $16.2 \%$ respectively. This difference was hypothesized to be due to differences in stringent and efficient systems of control between the market types. However, they later found that the difference was not statistically significant, and that confirmation with a larger sample was needed (Terio et al., 2010). A similar study in the Philippines with a much larger sample was also conducted, and found that there were no significant differences between hypermarkets and open-air markets in the presence of microbiological pathogens and enteric viruses (Vital, Dimasuay, Widmer, \& Rivera, 2014). Nevertheless, both studies showed the need to reevaluate monitoring processes for viruses and policies such as shelflife because of the relatively high rates of norovirus contamination in shellfish. 


\section{Common retail violations}

Garrido and Otwell (2009) state that the majority of food safety problems regarding shellfish originate from the inability to maintain the cold chain through harvest, transportation, and processing, as well as harvesting from unapproved waters. As such, maintaining records for shellfish from farm-to-fork are vital to ensure the best safety practices are being implemented throughout each stage. However, DeGolier et al. (2009) found that one of the most frequent violations among retail establishments selling shellfish involved failing to keep shellfish tags for 90 days (10\%). In fact, $10 \%$ of establishments did not have any method for organizing shellfish tags by date, which made it almost impossible to trace a specific batch of shellfish by date. Moreover, $32 \%$ of establishments were receiving shellfish repackaged that did not include harvest information, which is necessary for traceback investigations. Ultimately, Hazard Analysis and Critical Control Point (HACCP) programs are a vital barrier to shellfish contamination, but are being underutilized or improperly used among retail establishments. Another frequent violation was the commingling of shellfish species $(22 \%)$ (DeGolier et al., 2009). This is important because some shellfish such as molluscs are filter feeders and can filter wastes from other organisms in the tank. By the same token, it is important that bivalve molluscs are the first to receive the water supply if all tanks are connected from the same water source. In this way, bivalve molluscs do not filter the metabolic wastes from other shellfish (BCCDC, 2013). Consumer knowledge

Anacleto, Barrento, Nunes, Rosa, \& Marques (2014) found that consumer knowledge of bivalve mollusc safety varied depending on demographic. More specifically, they found that only $63.5 \%$ of people younger than $25 \mathrm{knew}$ about the risks associated with eating bivalve molluscs, compared to the average of $74.8 \%$. Moreover, Byrd-Bredbenner et al. (2007) found that young females outperformed young males significantly in food safety behaviours and knowledge. In this way, there seems to be a specific demographic of people (young males) that may be at a larger risk of illness from bivalve molluscs due to lack of knowledge and unsafe food handling behavior. However, little to no warning signs seem to exist in retail markets selling shellfish that may warn consumers of the risks that come with ingesting shellfish (Huss et al., 2000). These studies show a potential need to find ways to educate and warn consumers of a particular demographic the risks of ingesting molluscs.

Strengths and limitations of the literature review

The literature review included all types

of studies, but several limitations surfaced through the research. Firstly, the majority of the studies focused on shellfish at the harvesting stage, particularly with Vibrio parahaemolyticus or viruses. Less was found on shellfish safety at the retail level. Additionally, many of the sources on shellfish safety at the retail level were government guidelines or educational books. Thus, some studies used in this review were older than 10 years, which may make its findings less relevant to today.

Gaps in research, policy, and knowledge

Many of the studies in this review on shellfish safety at the retail level were done in different countries. Each country faces different challenges for shellfish safety at the retail level due to different populations, cultures, as well as how important seafood is to the countries' cuisine. For instance, shellfish are a much more widely used and culturally important food in Italy than it is in Canada. Another factor to take into account is that trends in shellfish illnesses may not even be entirely accurate because of differences between surveillance programs in different countries; one may be more sensitive than the other, so data may be inflated if you compare the two (Oliveira et al., 2011). Thus, one can expect the data on the consumers from both countries to be different as well. Ultimately, although studies with similar results from different places may serve to reinforce or strengthen that finding, it also has to take into account all the differences that exist. Therefore, it can be difficult to compare and apply findings from one country to another, including Canada. Evidence Review Conclusion

Despite their risks, shellfish are still a popular food choice among the public. The literature review showed that although there are a lot of barriers and guidelines in place to prevent contamination of shellfish in the 
harvesting stage, outbreaks still occur due to deficiencies in control measures or violation infractions by retail establishments. It seems that the biggest challenge for the retail stage is ensuring proper record-keeping of shellfish for retail. Additionally, monitoring indicators in the water used to hold bivalve molluscs are vital to prevent contamination in retail outlets. Thus, more attention may be needed on shellfish at the retail stage.

Other considerations from the literature review include consumer knowledge of bivalve safety. Research suggests that there may be a specific demographic to target for education. Policy development targeting young males may be something for further research and consideration in the future. Handling of the food by consumers is also an important stage in preventing food borne illness from bivalve mollusc consumption.

The rate of illness originating from shellfish seems to be rising in Canada and also throughout the world. These illnesses have a significant impact on both public health as well as the economy. Therefore, the continued development of shellfish safety at each and every stage of its production is essential to ensure minimal risk to public health. However, this endeavor requires a multi-faceted approach and an emphasis on studies regarding how the retail stage affects shellfish safety.

\section{Methods \& Materials Introduction}

This research study collected water quality data by taking and testing samples at facilities throughout Metro Vancouver with the cooperation of the Ministry of Agriculture, BCCDC, and BCIT. A null and alternative hypothesis for each parameter was tested in this proposed research project. For water temperature, the $\mathrm{H}_{\mathrm{o}}$ was that there is no difference in the mean water temperature values among processing plants and retail food markets. The $\mathrm{H}_{\mathrm{a}}$ was that there is a difference in the mean water temperature values among processing plants and retail food markets. For $\mathrm{pH}$, the $\mathrm{H}_{\mathrm{o}}$ was that there is no difference in the mean $\mathrm{pH}$ values among processing plants and retail food markets. The $\mathrm{H}_{\mathrm{a}}$ was that there is a difference in the mean $\mathrm{pH}$ values among processing plants and retail food markets. For dissolved oxygen, the $\mathrm{H}_{\mathrm{o}}$ was that there is no difference in the mean dissolved oxygen values among processing plants and retail food markets. The $\mathrm{H}_{\mathrm{a}}$ was that there is a difference in the mean dissolved oxygen values among processing plants and retail food markets. For nitrites, the $\mathrm{H}_{\mathrm{o}}$ was that there is no difference in the mean nitrite values among processing plants and retail food markets. The $\mathrm{H}_{\mathrm{a}}$ was that there is a difference in the mean nitrite values among processing plants and retail food markets. For turbidity, the $\mathrm{H}_{\mathrm{o}}$ was that there is no difference in the mean turbidity values among processing plants and retail food markets. The $\mathrm{H}_{\mathrm{a}}$ was that there is a difference in the mean turbidity values among processing plants and retail food markets.

Materials

The materials used in this research study included a LaMotte Fresh Water Aquaculture Kit $A Q-2$, which was a water quality test kit that included tests for temperature, $\mathrm{pH}$, dissolved oxygen, and nitrite. A HACH 2100P Turbidimeter was a portable meter used to measure turbidity of water in the holding tanks on site. A computer was needed to run $S A S$, which was the statistical analysis computer program used. A letter of support from the Ministry of Agriculture and the BCCDC was also used for entry and sampling at sampling sites. Any notes and test values recorded on site were recorded in a notebook. Water sampling bottles were used to take water samples from holding tanks for later testing. A cooler was used to store water bottles during sampling and transportation, while ice packs were used to store the samples at appropriate temperatures prior to testing. The cooler was checked using a thermometer to ensure that the interior temperature was below $4{ }^{\circ} \mathrm{C}$. The temperature recorded was approximately $2^{\circ} \mathrm{C}$.

Methods

Firstly, access to the sampling site was acquired. This was done in two ways. Firstly, samples were taken from retail markets by accompanying inspectors from the Department of Fisheries and Oceans as they did their inspection rounds. Lorraine McIntyre from the $\mathrm{BCCDC}$ also joined the first inspection with the DFO. Secondly, the Ministry of Agriculture 
contacted processing facilities and let them know that the author would be coming to take water samples. As a result, samples were taken from processing facilities by going to the site without an inspector. A letter of support from the Ministry of Agriculture and the BCCDC was available in order to gain access to the premises. The letter was given to the owner to help explain the project and gain consent in order to access their holding tanks.

Temperature was taken at the sampling site, while all other parameters were tested either at the BCIT lab or at the author's home, depending on the time at which testing was done. Water samples were taken using sterile water sampling bottles. The sampling bottle was not opened until just before sampling. After unscrewing the lid, the bottle was quickly submerged fully into the holding tank. Sampling did not occur near the surface or near any water outlet areas, but at half the height of the holding tank. In order to remove any air bubbles in the sampling bottle, the water bottle was tipped upwards while fully submerged. The lid was immediately screwed on after taking the bottle out of the holding tank (LaMotte instructions manual, n.d.). Water from the water sampling bottles was used to test all parameters except for temperature.

After sampling, water samples were stored in a cooler with ice packs within the vehicle used for transportation. Testing was done within 24 hours of sampling (United States Environmental Protection Agency, 2005). Below are the detailed descriptions of sampling and testing for each parameter. Except for temperature, all other procedures were taken from the LaMotte instruction manual (n.d.). Temperature

Using the thermometer provided in the LaMotte testing kit, the temperature of water in the holding tank was taken by inserting the thermometer in the water and holding it in place until stable temperature value was achieved (United States Environmental Protection Agency, 2012). If possible, the temperature was read through the holding tank glass. If not possible, the temperature was recorded immediately after it was taken out of the holding tank. Additionally, separate temperature tests were done at different depths in the same tank to see if there was a temperature gradient within the holding tank itself (HACH manual, 1995). The depths at which the temperature was taken was set at the surface and at half the height of the holding tank. The pilot study helped determine that there was not a gradient within the holding tanks.

$p H$

The tubes and $\mathrm{pH}$ indicator solutions provided in the LaMotte test kit were used. First, one tube was filled with sample water. Eight drops of Wide Range $4 \mathrm{pH}$ Indicator Solution were then added to the tube and swirled. The tube was inserted into the colour comparator (with the colour comparator disk on the right side) and the colour of the water sample was matched with the disc. The corresponding $\mathrm{pH}$ value was recorded.

Dissolved Oxygen

The equipment provided within the LaMotte test kit was used. Sample water was collected in the 60-mL BOD bottle, ensuring no air bubbles were present. 8 drops of Manganous Sulfate Solution and 8 drops of Alkaline Potassium Iodide Azide Reagent were added to the BOD bottle, stoppered, and mixed. Sulfuric Acid 1:1 was added and mixed. $20 \mathrm{~mL}$ of the prepared sample was then poured into a flask. 10 $\mathrm{mL}$ of the sample was titrated with sodium thiosulfate until the solution turned into a pale yellow colour. 8 drops of Starch Indicator Solution were added, and titration continued until the solution turned colourless. The level at which the sodium thiosulfate was sitting at in the titrator indicated the concentration of dissolved oxygen in ppm.

Nitrite

Nitrite was also tested using the LaMotte test kit. The test tube was filled to the $2.5 \mathrm{~mL}$ line with the sample water, and then diluted to the $5 \mathrm{~mL}$ line with Mixed Acid Reagent. Then, $0.1 \mathrm{~g}$ of Colour Developing Reagent was added to the sample and mixed for one minute. The sample was left to sit for 5 minutes, and the resulting colour was compared using the provided colour standard in the colour comparator. The corresponding results were recorded as ppm Nitrite Nitrogen. This number was multiplied by 3.3 to find ppm Nitrite. 


\section{Turbidity}

The HACH 2100P Turbidimeter was

used to measure turbidity on site. The measurement procedure was taken from the HACH 2100P Turbidimeter instruction manual (n.d.). The cuvet was filled with $10 \mathrm{~mL}$ of water sample and capped. The cuvet was then smeared evenly with the given silicone oil and placed into the instrument. After closing the lid, the turbidity measurement was read on the digital display.

\section{Calibration of Instruments}

Only the HACH 2100P Turbidimeter was calibrated prior to sampling and testing. The calibration procedure followed the Model 2100P Portable Turbidimeter Instruction Manual (1995). A clean sample cell was rinsed with dilution water several times. It was then filled to the marked line with dilution water. The sample cell was then inserted into the turbidimeter, ensuring the orientation mark of the cell was aligned with the compartment. The lid was closed, and I/O was pressed, which turned on the equipment. CAL was pressed, then READ was pressed. The sample cell with dilution water was taken out, and the standardized 20 NTU sample cell provided by HACH was inserted into the cell compartment. READ was then pressed. The same steps were followed for $100 \mathrm{NTU}$ and 800 NTU standardized cells provided by $\mathrm{HACH}$. Lastly, CAL was pressed to accept the calibration.

\section{Inclusion and Exclusion Criteria}

Sampling sites included all range cold water holding tanks, crustacean holding tanks, and shellfish holding tanks (BCCDC guideline, 2013). Range warm water tanks were excluded from sampling and testing. The reason for excluding range warm water tanks was because the tank water requirements differ (BCCDC guideline, 2013). All sizes of sampling premises were included so that results are indicative of all premises of that type. For instance, large supermarkets as well as small grocery stores were included for retail food markets. Furthermore, any premises within Metro Vancouver were included. Finally, any premises licensed by the Ministry of Agriculture and the Department of Fisheries and Oceans were included in the study.
Sampling sites were chosen based on a list of premises generated by the Ministry of Agriculture (MoA) for processing facilities and the Department of Fisheries and Oceans (DFO) for retail markets. The MoA generated the list of sampling sites based on the last ten processing facilities that were inspected. In this way, the sampling sites were chosen randomly. The DFO, however, generated a list of retail market sampling sites based on their inspection schedule, since I was accompanying DFO inspectors while they were inspecting these premises. Inspection sites were chosen based on randomness as well as intelligence or information gathered on facilities during past inspections (personal communications, 2016). The DFO could not expand any further on their selection process. In total, 8 processing facilities and 8 retail markets were chosen to be sampled. Ethical Considerations

The only ethical concern for this research project was the issue of consent to enter private property. Students have no authority to enter any place to take samples. Ways in which to gain consent were discussed earlier: by accompanying inspectors as well as providing a letter of support and a consent form.

\section{Results}

\section{Description of Data}

This research study measured water parameters in live retail fish holding tanks and compared the obtained data among two different types of premises that have and use holding tanks. These parameters include temperature, $\mathrm{pH}$, nitrites, turbidity, and dissolved oxygen. This research study was a quantitative study. Temperature, $\mathrm{pH}$, nitrites, turbidity, and dissolved oxygen are considered continuous numerical data.

Thirty samples for each parameter at each type of premise were taken, and the data entered into Microsoft Excel and SAS for descriptive statistics data and inferential statistics data. Given that some sampling premises had more than one holding tank, multiple samples were taken at that premise as long as the holding tank fell under the stated inclusion criteria. Thus, 30 sampling premises didn't necessarily have to be visited in order to obtain 30 samples. This made sampling a little 
more feasible due to time and budget constraints.

Descriptive Statistics

Microsoft Excel was used to generate the descriptive statistics from the data. Figure 1 shows the descriptive statistics chart for the data found in Appendix 1. Figure 2 shows the holding tank water requirements given by the BCCDC Retail Fish Holding Tank Guideline (2013).

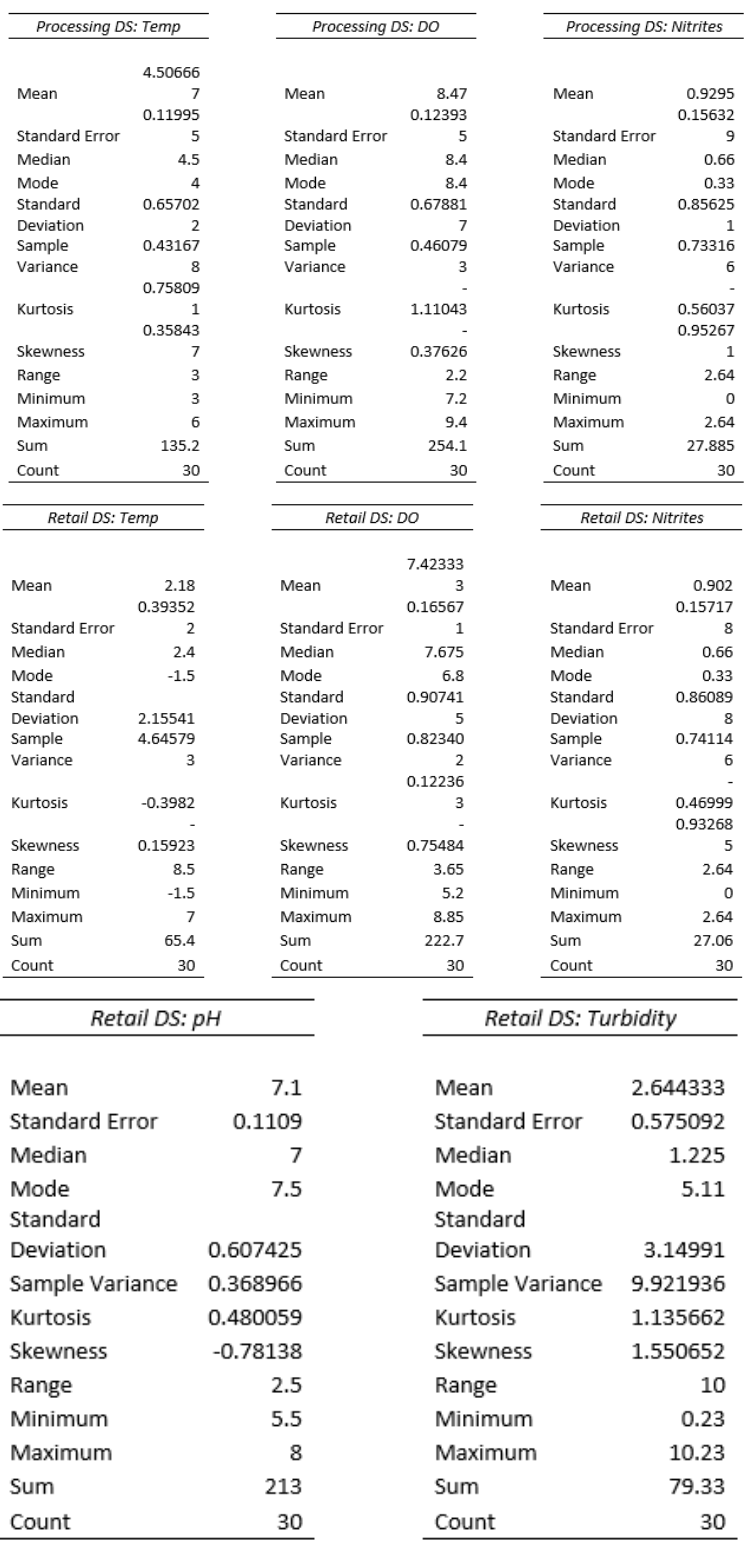

\begin{tabular}{|c|c|c|c|}
\hline \multicolumn{2}{|c|}{ Processing DS: $\mathrm{pH}$} & \multicolumn{2}{|c|}{ Processing DS: Turbidity } \\
\hline Mean & 7.266667 & Mean & 1.614667 \\
\hline Standard Error & 0.074792 & Standard Error & 0.3268 \\
\hline Median & 7.5 & Median & 0.995 \\
\hline $\begin{array}{l}\text { Mode } \\
\text { Standard }\end{array}$ & 7.5 & $\begin{array}{l}\text { Mode } \\
\text { Standard }\end{array}$ & 0.31 \\
\hline Deviation & 0.409654 & Deviation & 1.789956 \\
\hline Sample Variance & 0.167816 & Sample Variance & 3.203943 \\
\hline Kurtosis & -0.32749 & Kurtosis & 6.847167 \\
\hline Skewness & -0.11405 & Skewness & 2.439007 \\
\hline Range & 1.5 & Range & 8.09 \\
\hline Minimum & 6.5 & Minimum & 0.27 \\
\hline Maximum & 8 & Maximum & 8.36 \\
\hline Sum & 218 & Sum & 48.44 \\
\hline Count & 30 & Count & 30 \\
\hline
\end{tabular}

Figure 1. Descriptive statistics on Holding Tank Water Samples in Processing Facilities and Retail Market

\begin{tabular}{|lc|}
\hline \multicolumn{1}{|c}{ Parameter } & $\begin{array}{c}\text { Range Cold Water } \\
\text { Wanks } \\
\text { (fish species) }\end{array}$ \\
\hline $\begin{array}{l}\text { Specific Gravity } \\
\text { (Salinity) }\end{array}$ & Salt-water \\
\hline Temperature & $\begin{array}{c}1.024-1.029 \\
(24 \text { to29 ppt) }\end{array}$ \\
\hline pH & $<10^{\circ} \mathrm{C}$ \\
\hline Ammonia & $7.0-8.5$ \\
\hline Nitrite & $<10 \mathrm{ppm}$ \\
\hline Nitrate & $<2 \mathrm{ppm}$ \\
\hline Dissolved Oxygen & $<100 \mathrm{ppm}$ \\
\hline Coliform Count & $5 \mathrm{mg} / \mathrm{L}$ \\
\hline Turbidity (max) & $20 \mathrm{NTU}$ \\
\hline
\end{tabular}

Figure 2. Tank Water Requirements from the BCCDC Retail Fish Holding Guidelines

The mean values for all parameters in both retail and processing met the requirements set by the BCCDC (BCCDC guideline, 2013). However, the descriptive statistics shown in Figure 1 illustrate some similarities and differences between retail markets and processing facilities. Of the descriptive statistic summaries, the one parameter with the most significant difference between processing facilities and retail food markets was temperature, with means of 4.5 and 2.18 respectively. The mode for retail was -1.5 (degrees celcius), while the mode for processing 
was 4 . These temperatures are significantly different. The minimum temperature for retail was also much lower than processing, at -1.5 vs 3. These differences suggest a possible significant difference between the two locations for temperature.

The descriptive statistic summaries for nitrites and $\mathrm{pH}$ seem to illustrate little difference between processing and retail for both parameters. The mean, mode, minimum, and maximum values are all relatively similar.

The descriptive statistic summaries for turbidity and dissolved oxygen show a difference in the values between processing and retail for each parameter, but SAS will need to be used in order to more accurately determine if these differences are significant or not.

A couple outliers are also evident for turbidity in both processing and retail. The maximum values found are significantly higher than the means and the medians. Ultimately, the majority of the samples tested had low turbidity levels. However, some establishments (both processing and retail) had one or two tanks that were significantly more turbid than other tanks in the same establishment.

\section{Inferential Statistics}

This research project compared each parameter among the two different types of premises that utilize live retail fish holding tanks. Thus, the independent samples t-test was used. Additionally, a two-tailed test was used rather than than a one-tailed test. Should there be a significant difference among the two types of premises for the specified parameter, then the null hypothesis $\left(\mathrm{H}_{\mathrm{o}}\right)$ would be rejected and it would be concluded that there is a difference in the specified mean water quality parameter values between processing facilities and retail food markets. Finally, the p-value was set at $<0.05$.

Statistical Pack to be used

SAS was used for this research study.

Results Printed out from Statistical Package

Refer to Appendix II, III, IV, V, and VI.

Interpretation of Results and Reasoning for

Whether Parametric or Non-Parametric

Statistical Test was used

For temperature, some of the tests for normality show $p$-values $>0.05$, and therefore the data is not normally distributed. As a result, the Wilcoxon Rank sum test results are used. $\mathrm{P}<0.0001$ for both the one-sided and two-sided t-tests. Thus, $\mathrm{H}_{\mathrm{o}}$ was rejected and it can be concluded that there is a statistically significant difference between water temperatures in retail markets and processing facilities.

For dissolved oxygen, some of the tests for normality show $p$-values $>0.05$, and therefore the data is not normally distributed. As a result, the Wilcoxon Rank sum test results are used. $\mathrm{P}<0.0001$ for both the one-sided and twosided t-tests. Thus, $\mathrm{H}_{\mathrm{o}}$ was rejected and it can be concluded that there is a statistically significant difference between dissolved oxygen levels in retail markets and processing facilities.

For nitrites, none of the tests for normality show $p$-values $>0.05$, and therefore the data is normally distributed. Parametric results are used. Both equal and unequal variance show a p-value of 0.9017 , which suggests the data is not statistically significant. Thus, $\mathrm{H}_{\mathrm{o}}$ was not rejected and it can be concluded that there is no statistically significant difference between nitrite levels in processing facilities and retail markets.

For $\mathrm{pH}$, none of the tests for normality show p-values $>0.05$, and therefore the data is normally distributed. Parametric results are used. Equal and unequal variance show p-values of 0.2178 and 0.2185 respectively, which suggests the data is not statistically significant. Thus, $\mathrm{H}_{\mathrm{o}}$ is not rejected, and it can be concluded that there is no statistically significant difference between $\mathrm{pH}$ levels in processing facilities and retail markets.

For turbidity, none of the tests for normality show p-values $>0.05$, and therefore the data is normally distributed. Parametric results are used. Equal and unequal variance show p-values of 0.1250 and 0.1264 respectively, which suggests the data is not statistically significant. Thus, $\mathrm{H}_{\mathrm{o}}$ was not rejected and it can be concluded that there is no statistically significant difference between turbidity levels in processing facilities and retail markets.

\section{Discussion and Recommendations}

As depicted in the results section above, there was a statistically significant difference found between holding tanks in processing 
facilities and retail markets for the temperature and dissolved oxygen parameters. Statistical analysis of nitrites, $\mathrm{pH}$, and turbidity showed no statistically significant differences between processing facilities and retail markets for these water parameters.

Although there were significant differences found for temperature and dissolved oxygen, the means for both parameters were in compliance with the suggested levels from the BCCDC Guideline for Live Retail Fish Holding Systems. In both cases, processing facilities had a higher mean for temperature and dissolved oxygen than retail markets. Warmer and saltier water hold less dissolved oxygen than cold water and less saltier water (United States Environmental Protection Agency, n.d.).

Additionally, dissolved oxygen in water is used to break down organic material. If there is a lot of organic material, the dissolved oxygen can be used up (United States Environmental Protection Agency, n.d.). Taking this into account, the results suggest that either the holding tanks in retail markets were much saltier than their counterparts in processing facilities, or that the recirculation systems in processing facilities were more effective than the retail market holding tanks (such that the mean dissolved oxygen levels were higher than retail markets despite higher mean water temperatures found in processing facility holding tanks). Another possibility was that there is more organic matter found in retail market holding tanks compared to processing facilities. This may indicate a need to more closely examine the recirculation systems used in retail markets holding tanks, especially the smaller retail stores that often had older circulation systems in place, which may be starting to fail. The results may also indicate a need to pay more attention to the general sanitation of the holding tanks to ensure cleaner waters in holding tanks found in retail markets. Failing recirculation systems are a concern because below of certain level, shellfish mortality could increase due to a lack of dissolved oxygen. Dead shellfish increases meat deterioration, and increases the risk of microorganism contamination (in water with DO levels low enough to kill shellfish but enough to sustain microorganisms) (personal communication [class lecture], 2015). Increased organic matter in holding tanks is also concern because it may increase the risk of shellfish contamination, which may cause foodborne illnesses to consumers.

High temperature levels can lead to increased mortality of shellfish. However, despite the significant difference in temperature between processing facilities and retail markets, both means were below the recommended levels, as stated above. Therefore, there is no public health concern specifically regarding temperature. One reason for the higher mean temperature level in processing facilities was that the holding tanks were generally much larger than the holding tanks found in retail. Thus, it may be more difficult to keep temperatures as low as the retail mean of 2.18 ${ }^{\circ} \mathrm{C}$ due to the larger volume of water. Another reason was because of a limitation regarding thermometers used to measure the temperatures. This will be discussed below in the limitations section.

Although the mean value for nitrite levels for both processing facilities and retail markets were below the suggested value from the guidelines, 15 of the 60 samples had nitrite levels higher than the guidelines $(<2 \mathrm{ppm})$ (BCCDC, 2013). Nitrites are a less toxic conversion product of ammonia, which is a toxic by-product of fish metabolism and decaying organic matter. Nitrites and nitrates are converted by nitrifying bacteria in a bio filter that naturally forms in holding tanks. When there is a higher level of waste than what the bio filter can handle, ammonia levels will rise, which will affect fish mortality. Thus, high nitrite levels are indicative of overpopulation of species in the holding tank (BCCDC, 2013), as well as possibly high levels of ammonia. High levels of Ammonia found in shellfish may also indicate decomposition, due to mortality of the shellfish. Symptoms of Ammonia poisoning in humans include irritation, nausea, vomiting, and in extreme cases, respiratory problems (2009, Fraser Health). For instance, an incident of Ammonia poisoning was recorded after a customer consumed crab in Surrey, BC (2009, Fraser Health). It was determined that the crab died shortly after delivery, and natural decomposition allowed the Ammonia levels to increase. Nitrites, on the other hand, are less 
toxic than ammonia, but still considered toxic. High levels of nitrite are lethal to fish (Camargo $\&$ Alonso, 2006). As discussed earlier, dead shellfish are a health concern for consumers. Time of the season is another important factor to give consideration. Part of the sampling was taken around Chinese New Years, in which seafood sales increase significantly. Thus, many establishments also increase their supply, which may lead to overburdening holding tanks. This may indicate a need for increased attention or monitoring of retail markets during busy times such as Chinese New Years.

Turbidity levels were well below the maximum level of $20 \mathrm{NTU}$ as described by the BCCDC (2013). The mean levels of processing and retail markets were 1.61 and 2.64 respectively. The maximum turbidity level found was 10.23 . Therefore, there is little public health concern in regards to turbidity.

Although not directly related to the study, two observations were made throughout the course of visiting and sampling multiple facilities, particularly in retail markets. Firstly, there was often a lack of education regarding safe shellfish practices. For example, bivalves were found in the same holding tanks as nonshellfish species in approximately 5 of the 8 retail markets. More specifically, the bivalves would often be separated by a porous barrier. However, this porous barrier allowed the bivalves to share the water with other nonshellfish species. The BCCDC Guideline for Live Retail Fish Holding Systems (2013) states that bivalves can filter in wastes from other products in the tanks because they are filter feeders. When questioned, the manager often did not know of this recommendation. Another observation was that many retail markets did not have an organized way of keeping records and shellfish tags, such that it would have been extremely difficult, if not impossible, to perform traceback investigations in the event of a foodborne illness outbreak. A similar problem was also found in a study performed by Degolier et al. (2009). This disorganization can be improved through more detailed and prescriptive HACCP plans, and for employees to be more knowledgeable of what is in the HACCP plans.

\section{Limitations}

Due to feasibility, one sample was equated to one holding tank, regardless of which facility. As a result, multiple samples were taken from each single establishment. This is a potential limitation because some establishments were more generally sanitary, and thus it affected all their holding tanks, not just a single holding tank. Therefore, some establishments would yield samples that were more clean (or conversely more dirty) regardless of which holding tank was used for sampling. If pursued in the future, it may be more accurate to equate one sample to one facility.

A portable aquaculture kit was used to test the water samples, and cannot be expected to be as accurate as a laboratory. Some of the methods used, such as the dissolved oxygen required some qualitative measuring that were not very consistent in nature. For instance, part of the procedure required the addition of sodium thiosulfate until the solution turned from yellow to pale yellow. Also, the tests were done in a home environment rather than a lab environment due to feasibility. The school laboratory was not available because the sampling would often occur in the evening. Since a lab environment affords a more consistent environment than a home environment, inconsistencies or errors may be found in the results. Access to the BCCDC laboratory analysis would have been ideal, although it was not be feasible.

Due to the time needed to travel and sample, often samples would be stored for extended periods of time, albeit properly in a cooler with ice packs. Despite proper storage, a delay between sampling and testing could have affected results such as dissolved oxygen, which ideally should be done at the location (U.S. Environmental Protection Agency, 1983). However, the Azide-Winkler method was used to test dissolved oxygen, and the procedure was too complex to be able to do immediately after sampling on site. Although the Azide-Winkler method is considered more accurate than a dissolved oxygen probe (Department of Ecology State of Washington, n.d.), using a probe allows for instant testing on site, which may have increased the accuracy of the dissolved oxygen measurements. 
Halfway through sampling, the thermometer seemingly stopped working accurately. This conclusion was made because the thermometer used would continually show the same range of temperatures (4-6 degrees Celsius), and showed significantly different temperatures than the thermal measuring device used by the DFO officers. Thus, the temperatures for 23 samples in retail markets used the infrared gun used by DFO officers, which was different than the thermometer used in the rest of the samples. Using two different measuring instruments may have affected the results due to differences in accuracy and precision of the instrument. Initially, a concern was raised that an infrared gun would not capture the temperature of the whole tank since it would only measure the surface temperature. However, the DFO officer (personal communications, January 23, 2016) stated that due to the recirculation system, the water temperature should be even throughout.

Facilities were selected based on the inspector's schedule. Retail markets were selected based on the DFO officer's schedule. Due to this, all locations were located in Richmond and Vancouver (Chinatown). Processing facilities were selected based on a list given by the Ministry of Agriculture. These facilities were located in Richmond and Vancouver as well. The processing facilities were chosen randomly by the Ministry of Agriculture. The DFO, however, chose the locations partially based on randomness as well as previous intelligence and information gathered on facilities during past inspections (personal communications, March 30, 2016), as mentioned in the methods section. As a result, the samples taken may not be indicative of all retail markets in Metro Vancouver because they may have come from facilities with problems historically. Ultimately, this may have led to water quality results to be lower than what may be found for all retail markets in Metro Vancouver. The high nitrite levels in 15 facilities may be the result of this non-random selection. Although most processing facilities were located in Richmond and Vancouver, retail markets all around Metro Vancouver were available. Therefore, since samples were only taken from retail markets in Richmond and Vancouver, may not be indicative of all of Metro Vancouver.

Finally, another limitation of this study was that since all processing facilities were contacted by the Ministry of Agriculture to get permission for the collection of samples, they were forewarned. As a result, some facilities may have cleaned and fixed any problems, which may not be indicative of what their water quality is normally like. The water quality results from the samples, then, may be better than the true level for processing facilities. All retail markets were not given warning prior to entry for sampling by the DFO, so they had no chance to prepare.

\section{Future Research Suggestions}

In the future, student research studies may also want to consider including holding tank water quality found in restaurants and compare them to processing facilities and retail markets. This study could reference the results from this study in order to make the comparisons. A similar study can also be conducted with additional water quality parameters, such as coliforms.

Alternatively, this study could be repeated except equating one sample to one premise, thereby removing the limitation mentioned earlier. However, the feasibility for a student may be difficult considering the amount of time and resources needed to visit so many locations.

As mentioned above, the lack of education and HACCP was observed in many of the facilities, particularly retail markets. Another future study could focus on these issues, most likely through a survey-type study. This study would survey the managers and/or owners of the facilities. It would also most likely require the assistance of inspectors just like this research study. Otherwise, it may be difficult to gain access to the facilities.

\section{Conclusion}

This research study compared the water quality of shellfish holding tanks between processing plants and retail markets in Metro Vancouver. 30 samples were taken from each type of establishment, and results showed that the differences in temperature and dissolved 
oxygen were statistically significant. The other parameters, which included nitrites, turbidity, and $\mathrm{pH}$, showed no statistically significant difference. Examination of the results concluded that the differences in dissolved oxygen may have been due to salt levels, failing recirculation systems, or higher levels of organic matter, which may be due to general sanitation or recirculation systems. Differences in temperature were concluded to be due to differences in water volume due to holding tank size, or due to inconsistencies from using two different thermal measuring devices. High levels of nitrites were a concern as well, especially from overcrowding of holding tanks, particularly due to Chinese New Years. Ultimately, giving more attention to these issues may lower mortality rates of shellfish, which may lower the risk to the public health from foodborne illnesses.

\section{Acknowledgments}

This research study was only possible with the help of the Ministry of Agriculture, BCCDC, and the Department of Fisheries and Oceans. More specifically, thank you to Vanessa Karakilic for her help as the supervisor of the project; Fred Shaw for the technical expertise; Lorraine McIntyre for originally pitching forth the idea as well as her assistance with the project; Brian Barker for his help in developing the project; Wayne Sparanese, Dave Hunchak, and Stella Lukman for their help contacting the processing facilities; and Arthur Demsky and Perry Powers for their assistance and generosity for bringing the author alongside inspections.

\section{Competing Interests}

The authors declare that they have no competing interests.

\section{References}

Anacleto, P., Barrento, S., Nunes, M. L., Rosa, R., \& Marques, A. (2014). Portuguese consumers' attitudes and perceptions of bivalve molluscs. Food Control, 41, 168-177.

British Columbia Centre for Disease Control. (2012). Bivalve shellfish safety: Restaurant operator advice. Retrieved from
http://www.bccdc.ca/NR/rdonlyres/468

C072F-F34E-4A1E-839F-

707AB1002FB4/0/Shellfishsafetyrestow neradvisev3.pdf

British Columbia Centre for Disease Control. (2012). Retail operations in stores and restaurants ( $2^{\text {nd }}$ ed.). Retrieved from http://www.bccdc.ca/NR/rdonlyres/52C 4C365-029C-4042-9E9A0DF7739041EE/0/ProvFishInspMan_Se c5.pdf

British Columbia Centre for Disease Control. (2013). Fish processing plants: Guideline for live retail fish holding systems. Retrieved from http://www.bccdc.ca/NR/rdonlyres/1F7F 584B-FFCB-442A-BD2A30CA90A09643/0/RetailFishHoldingTa nkGuidelines_Nov2013trs.pdf

British Columbia Centre for Disease Control. (2013). Guideline for live retail fish holding systems. Retrieved from http://www.bcit.ca/files/library/pdf/bcitapastyle.pdf

British Columbia Centre for Disease Control. (2014). British columbia annual summary of reportable diseases. Retrieved from http://www.bccdc.ca/bccdc/resources/ar 2014finalsmall.pdf

British Columbia Centre for Disease Control. (2015). Ongoing warm weather increases risk of illness associated with raw shellfish consumption. Retrieved from http://www.bccdc.ca/about/newsstories/news-releases/2015/ongoingwarm-weather-increases-risk-of-illnessassociated-with-raw-shellfishconsumption

Byrd-Bredbenner, C., Maurer, J., Wheatley, V., Schaffner, D., Bruhn, C., \& Blalock, L. (2007). Food safety self-reported behaviors and cognitions of young adults: Results of a national study. Journal of Food Protection, 70(8), 1917-1926.

Camargo, J.A., \& Alonso, A. (2006). Ecological and toxicological effects of inorganic nitrogen pollution in aquatic ecosystems: A global assessment. 
Environment International, 32(2006), 831-849.

Canadian Food Inspection Agency. (2015). Canadian shellfish sanitation program manual of operations. Retrieved from Canadian Food Inspection Agency website: http://www.inspection.gc.ca/food/fishand-seafood/manuals/canadian-shellfishsanitationprogram/eng/1351609988326/13516105 79883 ? chap $=0$

Coliforms, Total and E. Coli. (n.d.). In Most Probable Number (MPN) Method Manual. Retrieved November 8, 2015, from file://C:/Users/KelsonMah/OneDrive/B CIT\%20assignments\%20\&\%20projects/ DOC316.53.01218_8ed.pdf

Degolier, L., Ledin, K., Vargulich, G., Patnaik, J., Wilson, B., \& Vogt, R. (2009). Assessment of shellfish practices in licensed retail food establishments in response to increased vibrio illnesses in a landlocked area. Journal of Environmental Health, 72(3), 24-27.

Department of Ecology State of Washington. (n.d.). How to measure dissolved oxygen. Retrieved from http://www.ecy.wa.gov/programs/wq/pl ants/management/joysmanual/4oxygen.h tml

Faber, S. (2012). Saxitoxin and the induction of paralytic shellfish poisoning. Journal of Young Investigators, 23(1), 1-7.

Fish Inspection Regulations. (2012, January 1). Queen's Printer, Victoria, British Columbia, Canada. Retrieved from http://www.bclaws.ca/civix/document/id /complete/statreg/12_78

Fraser Health. (2009). Food safety newsletter. Retrieved from https://www.fraserhealth.ca/media/Food SafetyNewsletterSummer2009.pdf

Garrido, V. (2009). Hazard analysis and critical control point programs for raw oyster processing and handling. In Shumway, S. \& Rodrick, G. (Ed.), Shellfish safety and quality (pp. 295-316). Woodhead Publishing.
Gosling, E. (2015). Marine bivalve molluscs ( $2^{\text {nd }}$ ed.). Chichester, UK: John Wiley \& Sons. doi: 10.1002/9781119045212.ch12

HACH Manual. (1995). In Model 2100P Portable Turbidimeter Instruction Manual. Loveland, CO: $\mathrm{HACH}$ Company.

Heacock, H., Karakilic, V. (2015a). Module 5: Inferential statistics. ENVH 8400 Research Method Course Notes. Burnaby, BC: British Columbia Institute of Technology

Heacock, H., Karakilic, V. (2015b). Module 5: Descriptive statistics. ENVH 8400 Research Method Course Notes. Burnaby, BC: British Columbia Institute of Technology

Health Canada. (2012). Turbidity in drinking water. Retrieved from Health Canada website: http://www.hc-sc.gc.ca/ewhsemt/pubs/water-eau/turbidity/indexeng.php

Huss, H. H., Reilly, A., \& Embarek, P. K. B. (2000). Prevention and control of hazards in seafood. Food Control, 11, 149-156.

Joseph, S. (2015). Fish and shellfish safety. ENVH 4350 Food Equipment and Processing Course Notes. Burnaby, BC: British Columbia Institute of Technology.

LaMotte Test Kit Instruction Manual. (n.d.). In Fresh Water Aquaculture Kit AQ-2. Chestertown, MA: LaMotte Company.

Lee, R., Lovatelli, A., \& Ababouch, L. (2008). Bivalve depuration: Fundamental and practical aspects. FAO Fisheries Technical Paper, 511, 13-18.

Nelapati, S., Nelapati, K., \& Chinnam, B. K. (2012). Vibrio parahaemolyticus- An emerging foodborne pathogen- A review. Veterinary World, 5(1), 48-62.

Oregon Health Authority. (n.d.). Safe eating of shellfish. Retrieved from: https://public.health.oregon.gov/Healthy Environments/Recreation/Documents/Sh ellfish-safety.pdf

Oregon State University. (n.d.) Chapter 14: Coliforms, fecal coliforms and escherichia coli. Retrieved from 
http://seafood.oregonstate.edu/.pdf\%20L inks/Compendium/Chapter-14Coliforms-Fecal-Coliforms.pdf

Oliveira, J., Cunha, A., Castilho, F., Romalde, J. L., \& Pereira, M. J. (2011). Microbial contamination and purification of bivalve shellfish: Crucial aspects in monitoring and future perspectives- A mini-review. Food Control, 22, 805816.

Public Health Agency of Canada. (2014). Norovirus. Retrieved from the Public Health Agency of Canada website: http://www.phac-aspc.gc.ca/fs-sa/fsfi/norovirus-eng.php

Terio, V., Martella, V., Moschidou, P., Di Pinto, P., Tantillo, G., \& Buonavoglia, C. (2010). Norovirus in retail fish. Food Microbiology, 27, 29-32.

United States Environmental Protection Agency. (2012). 5.3 Temperature. Retrieved from http://water.epa.gov/type/rsl/monitoring/ vms53.cfm

United States Environmental Protection Agency. (n.d.). Dissolved oxygen. Retrieved from http://omp.gso.uri.edu/ompweb/doee/sci ence/physical/choxy1.htm

United States Environmental Protection Agency. (1983). Recommendation for sampling and preservation of samples, arranged according to measurement. Retrieved from http://sisbl.uga.edu/epatab1.html

Vital, P. G., Dimasuay, K. G. B., Widmer, K.

W., \& Rivera, W. L. (2014).

Microbiological quality of fresh produce from open air markets and supermarkets in the philippines. The Scientific World Journal, 2014, 1-7.

Wohlsen, T., Bates, J., Vesey, G., Robinson, W.A., \& Katouli, M. (2006). Evaluation of the methods for enumerating coliform bacteria from water samples using precise reference standards. Letters in Applied Microbiology, 42(4), 350-356. Retrieved from http://onlinelibrary.wiley.com/doi/10.11 11/j.1472-765X.2006.01854.x/pdf 